\title{
Citrus Sudden Death in Brazil ${ }^{1}$
}

\section{S.H. Futch, M.J. Beretta and K.S. Derrick ${ }^{2}$}

Citrus sudden death is a relatively new disease to Brazil, first confirmed as a problem in 1999. The disease was first reported in the northern part of the citrus production area located in the state of Minas Gerais and has since spread into the northern part of Sao Paulo State, which is the largest citrus-producing state in Brazil. This northern citrus production region has a hotter climate and is subject to greater moisture stress than the majority of Sao Paulo State. The cause of the disease is presently unknown, but it appears to be an infectious disease that affects trees budded on Rangpur lime with limited reports on Volkamer lemon being infected.

Trees affected with sudden death decline rapidly within weeks of initial visual symptoms, and the disease has been give the name "sudden death" or in Portuguese "morte subita dos citros" (Figure 1). To date approximately three million trees have been reported lost due to the disease. This three million trees would be equivalent to an area, if planted at Florida planting densities of 12.5 feet $x 25$ feet, of approximately 21,500 acres of planted groves.

A survey conducted in July - August 2002 by Funde Citrus, an industry regulatory agency,

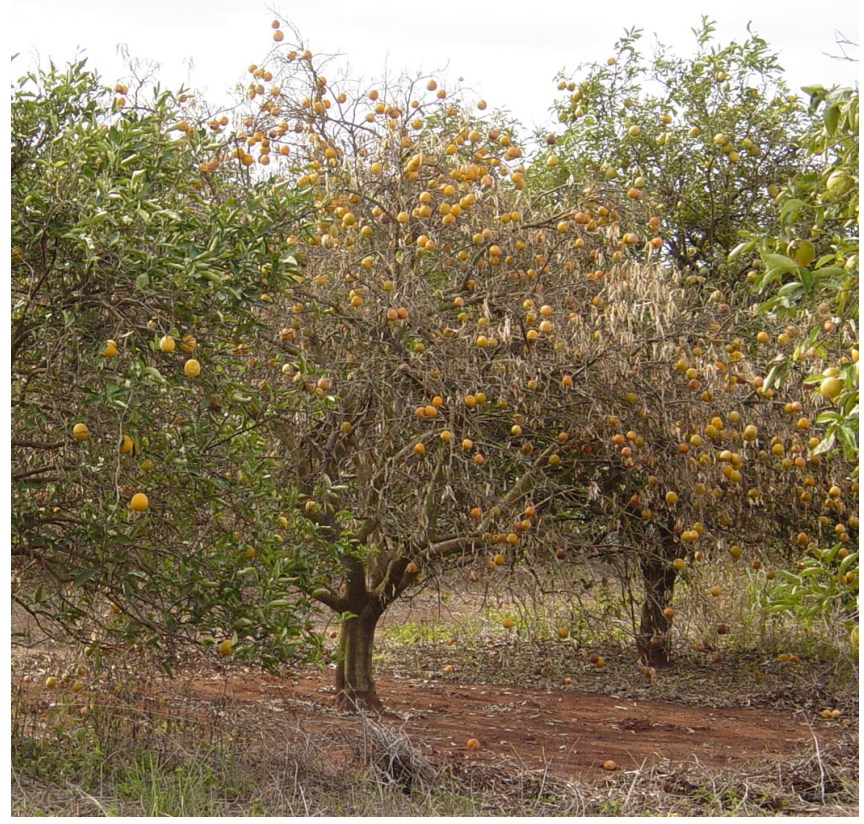

Figure 1. Trees with citrus sudden death, like these, decline rapidly within weeks of initial visual symptoms. To date, approximately three million trees have been reported lost due to the disease.

indicated 12 counties in the northern Sao Paulo and southern Minas Gerais states found more than 327,580 trees in 1,286 blocks infested. Most of the

1. This document is HS997, one of a series of the Horticultural Sciences Department, Florida Cooperative Extension Service, Institute of Food and Agricultural Sciences, University of Florida. Published February 2005. This research was supported by the Florida Agricultural Experiment Station, and approved for publication as Journal Series No. T-00658. Visit the EDIS Web site at http://edis.ifas.ufl.edu.

2. S.H. Futch, extension agent IV, Horticultural Sciences Department, M.J. Beretta, research associate, Plant Pathology Department, and K.S. Derrick, professor, Plant Pathology Department, Citrus REC, Lake Alfred, Florida; Cooperative Extension Service, Institute of Food and Agricultural Sciences, University of Florida, Gainesville, 32611.

The Institute of Food and Agricultural Sciences (IFAS) is an Equal Employment Opportunity - Affirmative Action Employer authorized to provide research, educational information and other services only to individuals and institutions that function without regard to race, creed, color, religion, age, disability, sex, sexual orientation, marital status, national origin, political opinions or affiliations. For information on obtaining other extension publications, contact your county Cooperative Extension Service office. Florida Cooperative Extension Service / Institute of Food and Agricultural Sciences / University of Florida / Larry R. Arrington, Interim Dean 
major cultivars, including Valencia, Natal, Pera, Hamlin, Westin, Pineapple and mandarins were found infected.

At the present time, sudden death appears to affect only trees on Rangpur lime and to a lesser extent on Volkamer lemon. With approximately $85 \%$ of Brazil's citrus industry planted on Rangpur lime rootstock, this poses a significant threat to their industry.

Sudden death causes a general but usually quick decline of the tree with a significant reduction in fibrous roots and a yellow stain in the bark (Figure 2) when thinly sliced from the lower trunk portion of the tree. The yellow stain is located in the phloem of the bark. Trees infested with sudden death will have fruit of normal size as compared to other diseases that cause fruit to be smaller than normal. Some have suggested that, based upon the spread pattern, an insect vector may be involved in the movement of the disease, but this has not been proven.

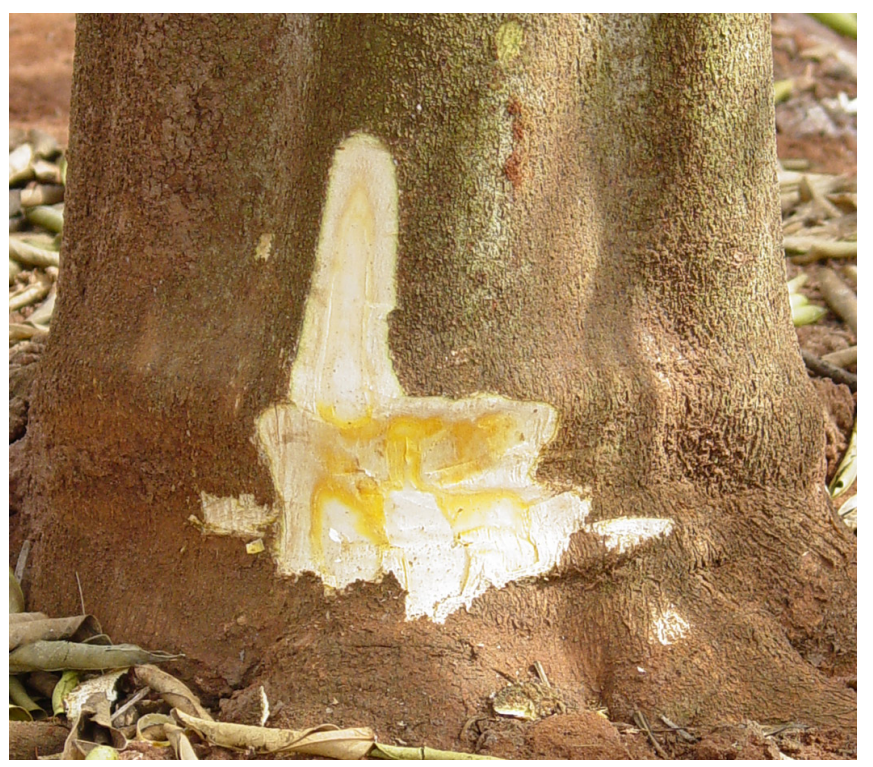

Figure 2. Yellow stain in the bark.

\section{Strategies To Combat Citrus Sudden Death}

Since it appears that the disease mainly affects trees on Rangpur lime, citrus growers are switching to rootstocks that appear to tolerate the disease in currently infested locations. Tolerant rootstocks currently being used include: Swingle citrumelo, Cleopatra mandarin, Sunki mandarin and trifoliate orange. However, the problem with switching to other rootstocks is that these alternative rootstocks are not as tolerant of the extreme drought conditions that appear in the fall and winter seasons in Brazil. With the movement to other rootstocks, growers are increasingly being forced to use irrigation to minimize the drought effects. This adoption of irrigation increases their grove establishment costs as well as the annual production costs. Water is limited and expensive due to expenses associated with irrigation well drilling depths.

An additional method of coping with the disease is the use of inarching with a tolerant rootstock on trees less than three to five years old and planted on Rangpur lime rootstock. Inarching is a process whereby a small seeding is planted near the trunk of the tree and grafted into the established tree above the budunion (Figure 3). Over a period of time, this new tolerant rootstock will grow and aid in replacing the old root system being affected by the sudden death. While inarching has shown some success, it is mainly limited to trees less than three to five years old that are free of visible disease problems. Trees greater than five years of age have died when inarched with a tolerant rootstock even when the trees were apparently free of the disease at the time of inarching. Inarching does add an additional cost of approximately $\$ 1.00$ to $\$ 1.40$ per inarch tree, and since it is suggested to place two inarchings per tree, the total added cost for this process comes to $\$ 1.00$ to $\$ 2.80$ per tree. Inarching is most successful when done during Brazil's rainy season to aid in the establishing of the new root system of the new tree.

Another recommendation is to use budwood grown in areas free of sudden death. Additionally, nursery trees are now required to be produced in enclosed structures to control citrus variegated chlorosis, which may limit the spread of sudden death. 


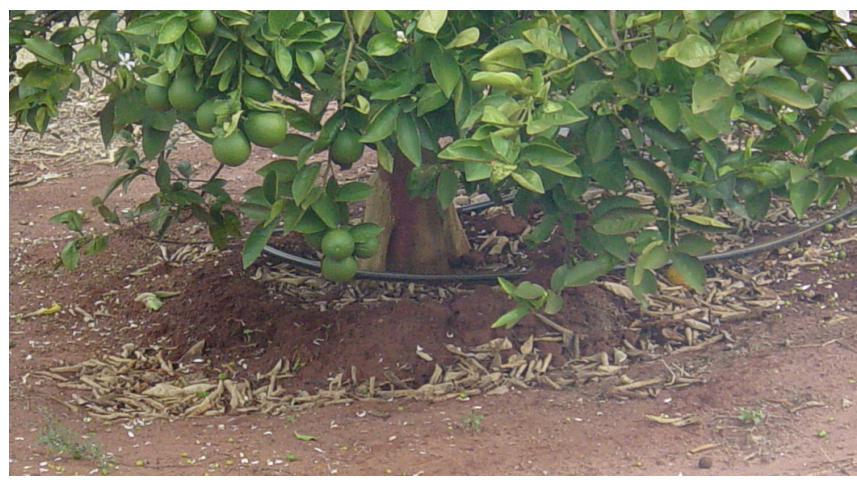

Figure 3. An inarched tree. Inarching is a process whereby a small seedling is planted near the trunk of the tree and grafted into the established tree above the budunion. Over a period of time, this new tolerant rootstock will grow and replace the old root system being affected by the sudden death. 